\title{
Analysis of Caesarean section rate in a government teaching institute based on Robson's ten group classification
}

\author{
Kavita Sambharam*, Mansi Lalit Verma, Pradip W. Sambarey
}

Department of Obstetrics and Gynecology, BJ Medical College, Pune, Maharashtra, India

Received: 29 August 2018

Revised: 15 October 2018

Accepted: 12 November 2018

\section{*Correspondence:}

Dr. Kavita Sambharam,

E-mail: drkavitass@gmail.com

Copyright: () the author(s), publisher and licensee Medip Academy. This is an open-access article distributed under the terms of the Creative Commons Attribution Non-Commercial License, which permits unrestricted non-commercial use, distribution, and reproduction in any medium, provided the original work is properly cited.

\section{ABSTRACT}

Background: Caesarean section rate is a qualitative health care indicator in India. With increasing rates of caesarean sections and no defined method to audit present institutes it is the need of the hour to use tools like Robson's classification to understand present system. The aim of this study was to determine the rate and analyse Caesarean sections in a tertiary care institute using Robson's ten group classification system.

Methods: This is a retrospective analytical study in which all Caesarean section done over a period of 3 years (July 2014-June 2017) were included which were performed in single unit (out of 6) of Department of Obstetrics and Gynecology of Sassoon General Hospital. Women were classified in 10 groups according to Robson's classification, using maternal characteristics and obstetrical history. For each group, authors calculated its relative size and its contribution to the overall caesarean rate.

Results: Total deliveries were 4750 out of which 985 were Caesarean section, incidence was calculated as $20.7 \%$. The main contributors to the overall Caesarean rate were primiparous women in spontaneous labour (group 1$\{18.3 \%\}$ ) and women with previous caesarean section (group 5- $\{34.9 \%\}$ ).

Conclusions: The Robson's classification is an easy tool to use and identify the current changing dynamics in any hospital setup. Its implementation as an obstetric audit can help lower the Caesarean rates and improve the standards based on WHO criteria.

Keywords: Caesarean section rate, Robson's ten group classification system

\section{INTRODUCTION}

In 1985, The World Health Organization (WHO) stated, there is no justification for any region to have a Caesarean section rate higher than $10-15 \%$. There is no empirical evidence for an ideal caesarean rate, but what matters most is that all women who need Caesarean sections actually receive them. ${ }^{1}$

Despite the lack of scientific evidence indicating any substantial maternal and perinatal benefits from increasing Caesarean section rates, and some studies showing that higher rates could be linked to negative consequences in maternal and child health, Caesarean rates continue to increase worldwide and have become a major public health concern. The lack of a standardized internationally-accepted classification system to monitor and compare Caesarean section rates in a consistent and action-oriented manner is one of the factors preventing a better understanding of this trend and underlying causes. According to the latest data from the National Family Health Survey 2015-16 (NFHS-4), Caesarean sections have doubled over the last decade across India. There is $16.7 \%$ rise in Caesarean section cases annually in India, one of the highest in the world, with $58 \%$ Caesarean section rate in Maharashtra itself. 
Due to this increasing trend of Caesarean section, our Government has made it mandatory for private hospitals empaneled with the Central Government Health Scheme to display the data of Caesarean section and normal deliveries. Government has directed State government to conduct periodic audits of private hospitals to ensure unnecessary procedures are not being conducted.

The Robson classification is a widely accepted, riskbased, ten-group classification system developed specifically to assess caesarean section rates. It allows comparison of clinically meaningful maternity population subgroups and the associated Caesarean section rates across institutions, countries, development groups, and time. ${ }^{2}$ This classification system categorizes women into 10 mutually exclusive groups, considering the following criteria: obstetric history (parity and previous Caesarean section), onset of labour (spontaneous, induced, or Caesarean section before onset of labour), fetal presentation or lie (cephalic, breech, or transverse), number of fetuses, and gestational age (preterm or term). The objective to conduct this study was to understand the characteristics of parturients coming to present hospital, their contribution to present Caesarean section rate and to formulate protocols to reduce the Caesarean rate, making it comparable to acceptable standards.

The aim of this study was to know the rate of Caesarean section in present hospital, to analyze the Caesarean sections based on Robson's classification and to determine the contribution and significance of each group on the overall number of Caesarean sections.

\section{METHODS}

This was a retrospective analytical study.

\section{Inclusion criteria}

- Authors included all Caesarean sections done over a period of 3 years (July 2014-June 2017) which were performed in single unit (out of 6 units) of Obstetrics and Gynecology Department of a government teaching institute in Western Maharashtra.

\section{Exclusion criteria}

- Authors excluded cases of hysterotomies $(<28$ weeks) and cases of ruptured uterus (scarred and unscarred).

Information was retrieved from the case files of all patients who underwent Caesarean section in the study duration from the medical record office.

All the data related to patient's age, parity, number and weeks of gestation, presentation, spontaneous/induced labour and indication of Caesarean section were entered in an excel sheet. Women were classified in 10 groups according to Robson's classification (Table 1), using the above information. ${ }^{2}$ For each group, authors calculated its relative size and its contribution to the overall Caesarean rate. Furthermore, authors analyzed the indications of CS in the groups that made the greatest contribution to the Caesarean rate.

Table 1: Distribution of cases of Caesarean section on the basis of the Rosson's TGCS. ${ }^{2}$

\begin{tabular}{|c|c|}
\hline Groups & Classification type \\
\hline Group 1 & $\begin{array}{l}\text { Nulliparous, singleton, cephalic, }>37 \text { weeks } \\
\text { in spontaneous labour }\end{array}$ \\
\hline Group 2 & $\begin{array}{l}\text { Nulliparous, singleton, cephalic, }>37 \text { weeks } \\
\text { induced labour }(2 \mathrm{~A}) \text { or Caesarean section } \\
\text { before labour }(2 \mathrm{~B})\end{array}$ \\
\hline Group 3 & $\begin{array}{l}\text { Multiparous (excluding previous Caesarean } \\
\text { section), singleton, cephalic, }>37 \text { weeks in } \\
\text { spontaneous labour }\end{array}$ \\
\hline Group 4 & $\begin{array}{l}\text { Multiparous without previous uterine scar, } \\
\text { singleton, cephalic, >37 weeks induced } \\
\text { labour (4A) or Caesarean section before } \\
\text { delivery (4B) }\end{array}$ \\
\hline Group 5 & $\begin{array}{l}\text { Previous Caesarean section, singleton, } \\
\text { cephalic, }>37 \text { weeks }\end{array}$ \\
\hline Group 6 & All nulliparous with a single breech \\
\hline Group 7 & $\begin{array}{l}\text { All multiparous with a single breech } \\
\text { (including previous Caesarean section) }\end{array}$ \\
\hline Group 8 & $\begin{array}{l}\text { All multiple pregnancies (including } \\
\text { previous Caesarean section) }\end{array}$ \\
\hline Group 9 & $\begin{array}{l}\text { All women with a single pregnancy } \\
\text { transverse or oblique lie (including } \\
\text { previous caesarean section) }\end{array}$ \\
\hline $\begin{array}{l}\text { Group } \\
10\end{array}$ & $\begin{array}{l}\text { All singleton, cephalic, < } 37 \text { weeks } \\
\text { (including previous caesarean section) }\end{array}$ \\
\hline
\end{tabular}

\section{RESULTS}

Total 24,862 deliveries were conducted during the study period in this institute including 7,235 Caesarean sections. Authors analyzed cases of single unit (out of 6) of Obstetrics and Gynecology Department from July 2014 to June 2017. These were 4750 deliveries in present study unit, out of which 985 were Caesarean deliveries. The incidence of Caesarean section in present institute was calculated as $20.7 \%$.

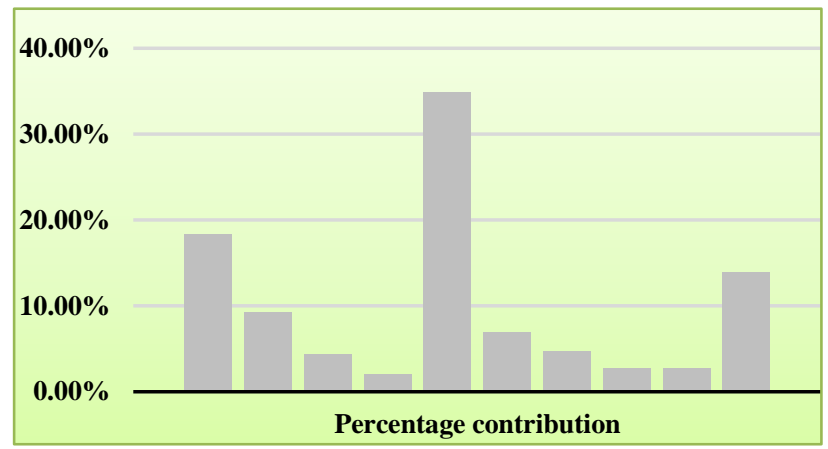

Figure 1: Distribution of Caesarean section based on Robson's TGCS. 
Analysis based on Robson's 10 group classification showed that Group 5 (previous LSCS, single, cephalic $>37$ weeks) made the greatest contribution to the Caesarean section rate $(34.9 \%)$. The second highest contributor was Group 1 (nulliparous, single, cephalic $>37$ weeks in spontaneous labour) $18.3 \%$ followed by Group 10 (all single cephalic <36 weeks including previous CS) $13.9 \%$ (Figure 1).

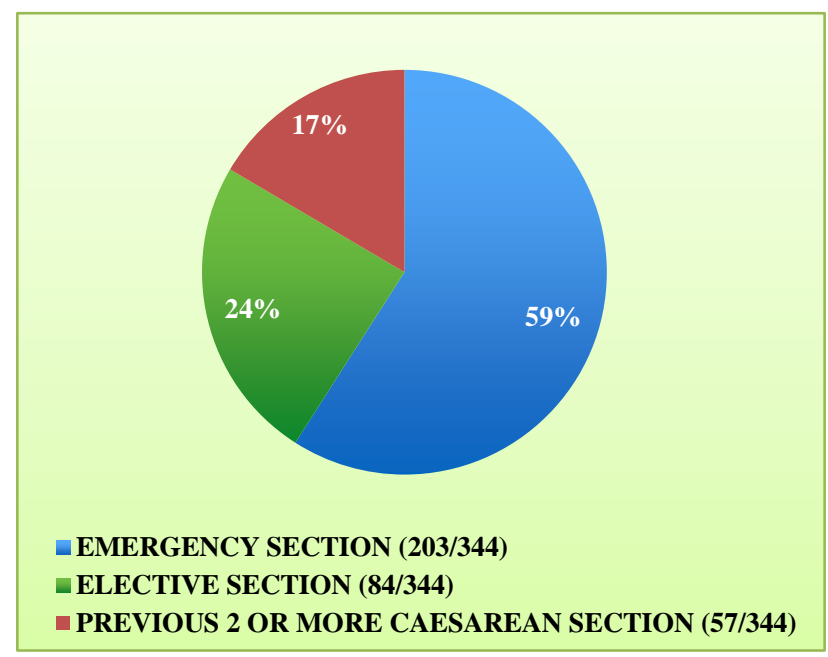

Figure 2: Analysis of group 5.

Authors analyzed Group 5 (previous Caesarean section, singleton, cephalic, >37 weeks) further. Out of 344 Caesarean sections done in this group, 203 (59\%) were emergency sections with scar tenderness being the most common cause whereas $84(24.4 \%)$ were elective caesarean sections and $57(16.5 \%)$ sections were done for cases with 2 or more previous caesarean sections (Figure 2).

Table 2: Distribution based on indication in group 1 (181/985).

\begin{tabular}{|l|l|l|}
\hline Indication & $\begin{array}{l}\text { Relative } \\
\text { size of } \\
\text { group }\end{array}$ & $\begin{array}{l}\text { Percentage } \\
\text { contribution } \\
\text { to group 1 }\end{array}$ \\
\hline Fetal distress & $120 / 181$ & 66.2 \\
\hline $\begin{array}{l}\text { Non-progress of labour } \\
\text { CPD with failed progress }\end{array}$ & $22 / 181$ & 12 \\
\hline $\begin{array}{l}\text { Co- morbidities- GDM, } \\
\text { pre-eclampsia }\end{array}$ & $4 / 181$ & 2.2 \\
\hline $\begin{array}{l}\text { Infertility } \\
\text { Anomalous uterus }\end{array}$ & $4 / 181$ & 2.2 \\
\hline $\begin{array}{l}\text { Others- BOH, placenta } \\
\text { previa, hydrocephalous, } \\
\text { hand prolapse etc. }\end{array}$ & $6 / 181$ & 1.6 \\
\hline
\end{tabular}

In group 1 (nulliparous, singleton, cephalic, $>37$ weeks in spontaneous labour), total cases were 181 out of which 120 cases were done due to fetal distress, 22 cases due to non-progress of labour, 22 cases due to CPD with failed trial and 17 cases due to causes like placenta previa, hydrocephalus, anomalous uterus, infertility, bad obstetric history etc. This group being present target group was studied in detail as reducing primary caesarean section rate will help reduce the number of previous section patients (Table 2).

In Group 10 i.e. all singleton, cephalic, <37 weeks (including previous caesarean section) (13.9\%), which included the preterm Caesarean sections, the common indications were severe preeclampsia, HELLP syndrome, abruption, placenta previa, preterm prelabour rupture of membranes with non-progress of labour and severe oligohydramnios.

\section{DISCUSSION}

With the increasing rate of Caesarean section, it is the need of hour to understand the changing dynamics of obstetric population and audit present obstetric management protocols. present hospital being a tertiary care centre is a referral unit for high risk cases which results in a higher turnover for Caesarean sections. On analyzing present data as per Robson's ten group classification, authors found that the major contributors were group $5(34.9 \%)$ and group $1(18.3 \%)$. This was consistent with the WHO survey done by Vogel et al. ${ }^{3}$ They described the so-called domino effect of Caesarean section use: as Caesarean section rates increase, more women in the obstetric population are in need of repeat Caesarean section, as indicated by the escalating contribution of group 5 to overall Caesarean section rates. Strategies to reduce this should include avoidance of medically unnecessary primary Caesarean section and introducing VBAC protocols with proper informed consent. A study by Lithorp et al with data of 137,094 (from 2000 to 2011) also found that the three largest groups (group 1,3 and 5) contributed the most to the total Caesarean section rate. ${ }^{4}$

Group 1: In present study mainly fetal distress, nonprogress of labour and CPD with failed trial were some of the indications. This can be lowered by reducing the inter-observer difference in interpretation of CTG by implementing frequent teaching workshops for the obstetric staff, by advocating and teaching residents about the use of instrumental deliveries and to prevent over diagnosis of fetal hypoxia purely on the basis of amniotic fluid and fetal heart rate assessment done clinically.

Group 2 and 4: Improved case selection for induction and prelabour Caesarean section could also reduce Caesarean section rates in Group 2A and 4A. Improved criteria and methods for inducing labour are not only safer for women but might also mitigate increased Caesarean section rates. Improvement of the use of evidence-based guidelines and clinical protocols for monitoring inductions is also important to optimise outcomes. ${ }^{5}$

Group 6-9: This had unavoidable obstetric indications and the data obtained was comparable to other national and international studies. ${ }^{3,5,6}$ 
Group 10: This group had 14\% contribution in present study which could be because of the high risk referred cases like abruption, severe preeclampsia, HELLP syndrome etc.

The ten Robson categories are mutually exclusive, totally inclusive, and can be applied prospectively, since each woman admitted for delivery can be classified immediately on the basis of a few variables that are generally routinely recorded. This system helps institution-specific monitoring and auditing, and offers a standardized comparison method between institutions, countries, and time points. ${ }^{7}$ The Robson classification has been used to analyze trends and determinants of caesarean section use in health care facilities in both high-income and low-income countries and has also been applied to state, national and international datasets, including data from eight Latin American countries in the WHO Global Survey of Maternal and Perinatal Health. ${ }^{7-}$ ${ }^{14}$ The limitation of this study is that it was a single centre study and there was referral bias, present hospital being a tertiary care centre.

\section{CONCLUSION}

Routine data collection in obstetric units of different hospitals, states, countries, can be used for application of the Robson's classification in different time frames. It is an easy tool to use and identify the current changing dynamics in any hospital setup. Its implementation as an obstetric audit can help lower the Caesarean rates and improve the standards based on WHO criteria. Some of the measures like avoidance of medically unnecessary primary Caesarean section, introducing VBAC protocols, implementing frequent teaching workshops for interpretation of CTG, advocating and teaching residents about the use of instrumental deliveries and devising protocols for criteria and methods induction of labour would help in bringing the rate of caesarean section to comparable standards in any setup.

Funding: No funding sources

Conflict of interest: None declared

Ethical approval: The study was approved by the Institutional Ethics Committee

\section{REFERENCES}

1. WHO. Monitoring obstetric care: a handbook. Geneva: WHO Press, World Health Organization, 2009.

2. Robson MS. Classification of caesarean sections. Fetal Matern Med Rev. 2001;12:23-39.

3. Vogel JP, Betran AP, Vindevoghel N, Souza JP, Torloni MR, Zhang J, et al. Use of the Robson classification to assess caesarean section trends in 21 countries: a secondary analysis of two WHO multicountry surveys. Lancet Glob Health. 2015;3(5):e260-70.

4. Litorp H, Kidanto HL, Nystrom L, Darj E, Essén B. Increasing caesarean section rates among low-risk groups: a panel study classifying deliveries according to Robson at a university hospital in Tanzania. BMC Preg Childbirth. 2013;13(1):107.

5. Mbaye M, Gueye M, Gueye MD, Niang NK, Moreau JC. Analysis of cesarean section rate according to Robson's classification in an urban health centre in Senegal. Int J Reprod Contracept Obstet Gynecol. 2017;4(4):1100-2.

6. Kazmi T, Sarva Saiseema V, Khan S. Analysis of Cesarean section rate-according to Robson's 10-group classification. Oman Med J. 2012;27(5):415-7.

7. Vogel JP, Betrán AP, Vindevoghel N, Souza JP, Torloni MR, Zhang $\mathrm{J}$, et al. Use of the Robson classification to assess caesarean section trends in 21 countries: a secondary analysis of two WHO multicountry surveys. Lancet Glob Heal. 2015;3(5):e260-70.

8. Tan JK, Tan EL, Kanagalingan D, Tan LK. Rational dissection of a high institutional cesarean section rate: an analysis using the Robson Ten Group Classification System. J Obstet Gynaecol Res. 2015;41(4):534-9.

9. Amatya A, Paudel R, Poudyal A, Wagle RR, Singh M, Thapa S. Examining stratified cesarean section rates using Robson classification system at Tribhuvan University Teaching Hospital. J Nepal Health Res Counc. 2013;11:255-8.

10. Abdel-Aleem H, Shaaban OM, Hassanin AI, Ibraheem AA. Analysis of cesarean delivery at Assiut University Hospital using the Ten Group Classification System. Int J Gynaecol Obstet. 2013;123:119-23.

11. Kelly S, Sprague A, Fell DB, Murphy P, Aelicks N, Guo $\mathrm{Y}$, et al. Examining caesarean section rates in Canada using the Robson classification system. J Obstet Gynaecol Canada. 2013;35(3):206-14.

12. Brennan DJ, Robson MS, Murphy M, O'Herlihy C. Comparative analysis of international cesarean delivery rates using 10-group classification identifies significant variation in spontaneous labor. Am J Obstet Gynecol. 2009;201:308.

13. Delbaere I, Cammu H, Martens E, Tency I, Martens G, Temmerman M. Limiting the caesarean section rate in low risk pregnancies is key to lowering the trend of increased abdominal deliveries: an observational study. BMC Preg Childbirth 2011;12:3.

14. Betrán AP, Gulmezoglu AM, Robson M, Merialdi M, Souza JP, Wojdyla D, et al. WHO Global Survey on Maternal and Perinatal Health in Latin America: classifying Caesarean sections. Reprod Heal. 2009;6:18.

Cite this article as: Sambharam K, Verma ML, Sambarey PW. Analysis of Caesarean section rate in a government teaching institute based on Robson's ten group classification. Int J Reprod Contracept Obstet Gynecol 2019;8:140-3. 